\title{
When Saving Time becomes Labor: Time, Work, and Technology in Homecare'
}

\section{Jenny M. Bergschöld ${ }^{2}$}

PhD Research Fellow, Department of Interdisciplinary studies of Culture, Norwegian University of Science and Technology, Norway

\begin{abstract}
The article shows how sociomaterial practices of ordering temporality can become part of labor and workers identities, when homecare workers who work with 'time-saving' technology experience a lack of sufficient time to do their work. The article offers the concept 'time labour' to describe this practice, and defines it as homecare workers methods of saving time, by cutting visits to care recipients as short as possible, and by using technology to strategically produce and maintain quantitative representations of themselves as skilled workers. The term time labor conceptualizes these methods as sociomaterial enactments of temporality that are an intrinsic part of the workers ability to perform that work as well as their ability to produce and maintain a professional identity. The article argues that the role of technology is never predictable, but always emerges in use, and suggests a turn toward domestication theory in practice theoretical studies of work with technology.
\end{abstract}

\section{KEY WORDS}

Demographic aging / Homecare work / Gerontechnology / ICT / Time labor / Welfare technology

\section{Introduction}

he reification of work into something that can, and should be quantified as clocktime, has enabled strong connections between time and money, and when clock-time becomes the taken for granted measurement of work, the human cost of that standard is rendered less visible (Dawson \& Sykes, 2016). After showing how aspects of care that do not lend themselves to quantification, standards and predetermined rationales are rendered invisible, Gherardhi and Rodeschini (2016) called for a turn to sociomateriality in studies of care work. This call can be understood as particularly pertinent in the context of the recent political implementation of 'welfare technologies' in Norway, Sweden, and Denmark. The idea is that welfare technologies will simultaneously increase the efficiency and quality of services. (Ministry of Health and Care Service, 2012). While the three countries share the common term 'welfare technologies', each country has its own definition. In Norway, the concept welfare technologies does not point to specific technologies but applies to any technology that facilitates the set objectives and in Norwegian homecare, the implementation of welfare technologies has translated to implementation of supposedly time-saving ICTs. Using technology to measure and control

\footnotetext{
${ }^{1}$ You can find this text and its DOI at https://tidsskrift.dk/njwls/index.

${ }^{2}$ Email: jenny.bergschold@ntnu.no or jenny.bergschold@gmail.com.
} 
that the services rendered do not exceed the standard timeslots allocated to homecare recipients is believed to free up time that can be spent caring for recipients of homecare (Ministry of Health and Care Service, 2012). In other words, time-saving ICTs have become embedded in a political discourse that describes welfare technologies as carriers of pre-determined 'effects' in the shape of efficiency and increased quality. However, so far little is known about how these time-saving technologies shape, and are shaped by homecare work in practice.

Others have commented that the lack of social research on the time-saving ICTs in Nordic homecare is significant (Brown \& Korczynski, 2010). There are, however, at least four notable exceptions. In a study on Swedish homecare, Hjalmarsson (2009) describes how the technology participates in the rationalization of homecare work in a manner that runs counter to the egalitarian ideals of the welfare state. Korczynski and Brown (2010) describe how Swedish homecare managers use information rendered by the technology to enforce tayloristic ideals of efficiency and discipline homecare workers when they spend too much time with homecare recipients. Hjalmarsson (2009) and Korczynski and Brown (2010) show that the technology is used to increase financial rationalization at the expense of quality in homecare work. In line with this, Bergschöld (2016) describes how the technology adds to, rather than expedites, the time Norwegian homecare workers spend on administrative work. Vuokko (2006) shows how the technology's capacity of allowing homecare workers to document visits to homecare recipients without returning to the office perpetuates the lack of time. In Vuokko's study, the technology added to the workload rather than expediting existing practices because the implementation of the technology brought with it an expectation that all visits would be documented which had previously not been the case. Together, these studies highlight the importance of not taking the time-saving capacity of this technology for granted. However, only Bergschöld (2016) takes sociomateriality explicitly into account and none of the studies are explicitly concerned with the relation between sociomateriality, time, and care work.

Studies of Nordic homecare work that have dealt with time have primarily been concerned with the psychosocial implications of lacking time and describe stress (EricsonLidman et al., 2013), long-term sick leave (Allebeck \& Mastekaasa, 2004; Næss \& Wærness, 1996), as well as its implications. For instance, unwillingness to enter into and remain in the occupation (Næss, 2003). Several studies have showed that the relation between time and care work is relational and reciprocal. For instance, Zerubavel (1979, 1981) describes how the time-span of internships and shifts both order and are ordered in practices of nursing. Lee-Treweek (1997) shows how auxiliary nurses resist hierarchical structures in a nursing home by performing their work as swiftly as possible. Drawing on the concept of 'time work' (Flaherty, 2003), Hirvonen and Husso (2012) show how Finnish homecare workers manage their experiences of lacking time. However, the concept time work is limited to descriptions of care workers attempts of managing emotional experiences of passing clock-time. When Hirvonen and Husso (2012) refer to care professionals methods of doing 'time work', they are referring to the work care workers do to maintain their identities as competent care workers when the limited time they spend with homecare recipients conflicts with their own ethical ideals of care.

This study contributes to understanding of the relation between timesaving ICTs, time, and care work by presenting a case of homecare workers in Norway who work with a 'time-saving technology' called Life Care Mobil Pleie (LMP). In this study, I ask: 
How do the homecare workers describe their methods for saving time, and how does the role of the technology emerge in relation to these methods? While these homecare workers describe that they lack a sufficient amount of time to do their tasks, they actively contradict the notion that this lack of time leads to experiences of stress. Instead, these homecare workers argue that they can make time to enable themselves to do their job. Thus, this case contrasts against previous studies of Nordic homecare work that describes homecare workers experiences of lacking a sufficient amount of time to do their work in terms of stress and stress-related implications. Additionally, these homecare workers reject the notion that the LMP has any capacity to influence how much time they spend with care recipients, describing it instead as a means that they strategically use to exhibit their professional identities as skilled in the art of ending visits to care recipients swiftly. Thus, this study challenges Brown and Korzynski's (2010) and Hjalmarsson's (2009) claims that that the disempowerment of homecare workers is a given and inherit quality of time-saving ICTs and further highlights the need for studies that take a sociomaterial approach. Finally, I offer the term time labor to describe the homecare workers methods of saving time and using the technology to strategically produce and maintain quantitative representations of themselves as skilled workers. The term time labor conceptualizes these methods as sociomaterial enactments of temporality that are an intrinsic part of the workers ability to perform that work as well as their ability to produce and maintain a professional identity. This does not mean to imply that this article provides an exhaustive account of time labor, merely that I describe a phenomenon that may prove useful in the further exploration of the role of presumably timesaving technologies in work.

The following sections describe the theoretical framework, methods, and case description, including a more detailed description of the LMP, before proceeding with the analysis and finally the conclusion.

\section{Theory}

Gerardi and Rhodeschini (2015) propose a practice-based approach to understanding caring as a situated activity where organizational reality is understood as constantly in the making, as opposed to something that is stable and pre-existing. They draw inspiration from studies that reject the notion that norms in care pre-exist action (Berg \& Mol, 1998; Mol, 2002, 2008; Mol et al., 2010) and argue for a perspective on care that acknowledges that organizational reality does not proceed in a linear manner, but is relational to the situated context, including materialities such as technology (Gherardi \& Rodeschini, 2016). From this perspective, care is understood as the practical enactment of shared and situated knowledges and understandings that guide action. Thus, it is not what is objectively true or regarded as right or wrong by others, for instance managers, that is of interest, but whatever it is that is treated by actors as if it were true or appropriate behavior in the context of their descriptions of their own situation.

A practice is a type of behavior that consists of several interconnected elements, for instance embodied activities, understandings, things, and their use and motivational knowledges (Reckwitz, 2002). The behaviors that make up a practice can be understood as nexuses of doings and sayings. To say that doings and sayings make up a practice means to say that doings and sayings are linked in a characteristic way. Schatzki (1996) identifies what he calls three major avenues of linkage; understandings of what to say 
or do in a given situation, formalized rules or instructions (insofar as they are followed) and motivational - or 'teleoaffective' understandings. Practitioners share understandings of the circumstances of their everyday life that result in actions that, while differing in terms of personal style, serve to produce and reproduce patterned practices (Schatzki, 2001, 2011). From this perspective, time-saving can be understood as made up of a variety of methods for saving time, processes in which the daily enactment of visits to homecare recipients co-configure time and care are co-constituted as the final homecare service product that is delivered to the public. With this approach, it is not what is objectively true that is of interest for empirical exploration, but whatever it is treated by actors as if it were true as they go about understanding the circumstances of their own situation and selecting their appropriate responses. In analysing the homecare workers descriptions, I do not treat them as fact or fiction, but as verbalized sensemaking of understandings that guide action.

Individuals who engage in integrative practices do not only share particular understandings of actions in certain situations. They also share a relation to regulations, instructions, and rules that apply to the domain where the practice is enacted. Additionally, they may share perspectives, tasks, and beliefs (Buch et al., 2015), or as in this case technology. By drawing on an understanding of temporality, in this case the duration of visits, as something that is constituted in practice it becomes possible to approach it as something that is 'done' (Shove et al., 2009). In studying how the homecare workers describe how they act to save time and use the LMP, I do not view these these statements as a way of studying the practice itself, but as a way of studying the homecare workers verbalized sense-making of their strategies of action (Swidler, 1986, 2006) as they deal with lack of time and use the LMP in the course of performing their work.

In this study, I was interested in how homecare workers understood time-saving; additionally, I was curious about how time-saving is entangled with the LMP. In this domain, the 'shared explicit regulations' are represented by the instructions relating to how the homecare workers studied here are expected to use the LMP. I wanted to understand how the homecare workers understand the measurement and registration of the time they spend in visits to homecare recipients. In other words, I was interested in the sociomateriality of time-saving insofar as it related to homecare workers understanding of the LMP. That is, I was interested in how the LMP is enacted.

The term domestication refers to how technologies, much like pets, need to be socialized (Lie \& Sørensen, 1996). Even though technologies are ready-built when they leave the factory, this does not mean that they are finished as sociocultural products (Sørensen, 1996). The introduction of new technology into an organization is a complex sociomaterial process where technologies are enacted, symbolically as well as practically. This process occurs as users make sense of artefacts and their place in practices (Berker et al., 2006; Sørensen \& Lie, 1996). The role of technology emerges through the work it is or is not put to, the practices it becomes part of as well as the means through which it may be employed to this end and the user identities it enables or disables. When practices of use are constitutive of patterned consistencies that support a particular version of the technology over time, its role may stabilize overtime (Sørensen, 1996; Sørensen et al., 2000). Like practice theory, the domestication approach to technology rejects structuralist explanations where reality pre-exists situated action and sense-making - in other words - users matter to technology (Oudshoorn \& Pinch, 2003). Domestication studies are explicitly concerned with reductionist notions that posit technologies as simple and 
straightforward solutions with the capacity to unproblematically order human action and provide 'fixes' (Hughes, 1987) to social problems. The implementation of the technology studied here is an example of such reductionism. The idea that it can provide more time for care relies on the notion that it will 'fix' time in care through increased control of how much time homecare workers use in visits to care recipients.

\section{Method}

The empirical material for this study was gathered through ethnographical fieldwork in a homecare unit in Norway. The research participants were nine administrative and operative homecare workers at a homecare unit in Norway who self-identify as skilful time-savers. I accompanied these homecare workers throughout their working day from the point when they came to work, to when they left for the day. I observed what they did, particularly when using the technology and continuously made fieldnotes. In the aim of unfolding what homecare workers treated as true, questions were continually asked in direct relation to activities of making time and aimed toward extracting the homecare workers' understanding of their situation and choices. These conversations were unstructured and active in the sense of Holstein and Gubrium (1995). Each day of fieldwork lasted for an average of 8 hours each, and were performed as the homecare workers were performing their work. Questions were asked in direct relation to ongoing decision-making with regards to time-saving, and concerned the rationale for privileging some choices over others. All conversations were audiotaped and transcribed ad verbatim. Translation of quotes from Norwegian to English were made by the author. All translations privilege clarity of meaning over the verbatim. The ethical considerations of this study were reviewed and approved by the Norwegian Social Science Data Services (NSD). Written and verbal information about the study was distributed to all participants. Verbal consent to my presence as well as to being audio recorded and quoted for the purposes of research was obtained from all research participants. This consent procedure is in accordance with Norwegian law, as well as the general ethical guidelines issued by NSD, and the instructions provided to me by NSD at the start of this study. Names have been altered to ensure the homecare workers anonymity. Because this study touches on a sensitive topic that could potentially lead stakeholders like managers to attempt to identify research participants, I would like to stress that the information provided in this study cannot be used to accurately identify any of the research participants. Not all research participants whom I accompanied are part of the sample described in this article. Furthermore, the fictional names I use are deliberately chosen because they do not reflect the age of the research participants. Additionally, I have taken care to omit any fieldnotes, footage, information about time-periods, and geographical locations that could otherwise have been used to falsely or accurately identify any of the research participants.

The analytical procedure is inspired by social constructionist grounded theory (Charmaz, 2014; Clarke, 2005). Transcriptions and fieldnotes were first analyzed using open coding (Clarke, 2005) and abduction (Reichertz, 2007). This process led to the identification of timesaving as a practice that involves methods for cutting visits to homecare recipients short, and methods of using the technology after finishing a visit to a care recipient. I used theoretical sampling (Charmaz, 2014) to conduct a focused coding of 
fieldnotes and transcriptions to further explore how the homecare workers talk about saving time by cutting visits to homecare recipients short and how they talk about and use the timesaving technology. I drew on practice theoretical work on time to interpret the homecare workers descriptions of their reasons for cutting visits to homecare recipients short, as verbalized sense-making of workers situated knowledge of methods of how to order temporality and 'make time'. I drew on domestication theory to interpret the homecare workers descriptions of how they use the LMP as a way of enacting the role of this device as well as their own identities by using the LMP as a means of selfrepresentation. This switch in theoretical lenses is similar to what (Nicolini, 2009) refers to as zooming in and zooming out and that enabled me to alternately foreground and bracket different aspects of the empirical material to construct the two categories from the themes identified in the first stages of the coding process. The structure of the codes and categories is reflected in the structure of the analysis. The two main categories are represented by the two main headlines in the analysis, and the codes that are constitutive of those categories are represented by the lesser headlines that follow hierarchically.

\section{Case description}

The LMP is an app that is installed on smartphones that are distributed to the homecare workers at the start of the working day. The app contains the homecare workers schedule and details the tasks that should be performed during each visit to the different care recipients, as well as information on how much time the homecare workers are expected to spend performing those tasks, and a feature that measures and registers the time they do spend during visits to homecare recipients. This measurement is displayed on the screen where it is visible to the homecare workers during the visit in the form of a running clock that starts at 00:00 and counts upwards. When the running clock reaches the amount of time allocated to that particular visit on the schedule, the device signals to the homecare worker by shifting the colour of the numbers from green to red. When the homecare worker leaves the homecare recipients home the count is stopped and the measurement is saved to a remote server where it can be accessed by administrative staff and managers.

The LMP is produced by Tieto, the leading provider of ICT services for the welfare sector in the Nordic countries (Tieto Norway, 2015a). Together, these functions are meant to be constitutive of what the producer markets as the LMP's capacity to create more time for care, by enabling a change in previously time-consuming and thus also expensive routines (Tieto Velferd, 2016a). In this narrative, the LMP is presented as a technological innovation that replaces analogue routines where homecare workers would keep notes using pen and paper throughout the day, and digitalize the documentation at the end of their shift using stationary computers at the office. This is portrayed as a time-consuming process when homecare workers have to wait their turn to use stationary computers that are shared with other homecare workers (Tieto Velferd, 2016b).

Public debate in Norway on this particular device has revolved around the issue of whether or not the countdown is constructive or detrimental of the quality of homecare. Describing the countdown as a 'stopwatch', representatives of the labor union argue that the technology forces homecare workers to rush through visits to homecare recipients and do the bare minimum, rather than tailor services to homecare recipients' 
needs (Sandberg \& Prestegård, 2015). On the other side of this debate, municipal representatives for the right wing party argue that the device is merely a phone, increases the quality of homecare, and bears no likeness to a stopwatch (Prestegård, 2015). While anecdotal, the descriptions of the technology in this debate highlights that end-users and political decision-makers have wildly different understandings of what this technology is, and what it does even after implementation. As I have argued elsewhere [blinded for review], the uncertainty of how well welfare technologies live up to the objectives of their implementation highlights the importance of empirical studies of the work they do in the everyday lives of those whom they are supposed to benefit.

In the homecare unit where the fieldwork for this study was performed, the LMP did not replace a pen and paper routine, but an older version of the same software. This replacement was experienced as so uneventful that most still used the acronym 'PDA' even when referring to the new device. PDA is an acronym for 'Personal Digital Assistant', a precursor to smartphones. In comparison to smartphones, PDAs were thicker, clumsier, and often lost the wireless connection to the remote server where all information is stored. Traits that had earned it a vernacular nickname among the homecare workers at this homecare office - 'Pinligt Dårlig Apparat'. ${ }^{1}$

At this homecare unit, in similarity to many other municipal homecare organizations in Norway, the PDA was implemented during the years 2006 and 2009 (Evjen, 2008). ${ }^{2}$ But while the local vernacular for this device refers only to the hardware, the change that this implementation brought about was related to its software - Gerica Mobil Pleie (GMP). The GMP was an early version of the LMP that offered a slightly more limited set of functions. ${ }^{3}$ In difference to the LMP, the GMP did not come with a running clock that timed the interval between start and finish of the visit to clients automatically. Instead, the homecare workers registered the time they had spent by entering the information manually at the same time that they documented all other relevant details pertaining to the visit.

In technical terms, the implementation of the LMP consisted of two changes. The switch in hardware, which is the 'phone' referenced by the city council in the public debate previously described, and the introduction of an automated running clock that measures how much time the homecare workers spend with care recipients, and compares this measurement to how much time they are supposed to spend. If the estimated time is exceeded, the numbers turn red. If the visit is finished, and documented, within the estimated timeframe, the numbers remain green. This is the 'stopwatch' referred to by the union representatives in the same debate.

In researching the situated history of the LMP at this homecare unit, it soon became obvious that even though the replacement of the GMP had happened recently, the LMP was not considered 'new' technology. Even when specifically asked about the obvious opportunities for the 'stopwatch' to be constitutive of control and surveillance, the homecare workers expressed that the LMP did not control the duration of visits to clients or even how time is registered.

This lack of control was described as the result of a particular feature that allows the homecare workers to control the device, rather than the other way around. This feature affords the homecare workers the possibility to change the measurement before saving it. While I was unable to find any reference to this feature in public debates, earlier research, or on the producers website, it is referred to in organizational documents that outline how homecare workers should use the LMP. 
Double click on the care recipients name. Then activate the screen-lock. The clock then starts to run in relation to time used with the care recipient. [...]

When logging out after having documented the work with the care recipient, the time spent is stored. This is not an attempt to surveil the employees, but a tool for planning.

$[\ldots]$ it is important that the time spent with the care recipient is accounted for and it is not permitted to 'cheat'4 the clock. Changing the start or end time of the visit, backwards or forwards is forbidden.

When the administrative staff make decisions on how much time a care recipients needs from the homecare services per visit, they use the digitized records of time as a tool to predict how much time homecare workers will need to perform future visits to the same homecare recipient. It is this practice the instructions for use of the LMP refer to as 'a tool for planning'.

In addition to highlighting that the knowledge about this feature is shared by organizational decision-makers, this document is also descriptive of the material limits of the 'stopwatch'. While the technology is theoretically capable of measuring the time that homecare workers spend in client interactions, this capacity is in practice, hinged on the homecare workers willingness to activate the clock before entering the care recipient's home and refraining from changing the measurement when documenting the proceedings.

\section{Understanding time-saving}

The following text is a collection of excerpts from my field notes.

After Vivian parked the car at the side of the street we started walking across the lawn towards the entrance of the apartment building. It's a chilly October morning in the north of Norway and while there isn't any snow yet, the frost on the grass glitters in the sunlight. Trying to keep up with Vivian's brisk stride I'm silently cursing my choice to wear sneakers this morning as my feet are now both wet and cold. Glancing down at my her shoes, thinking I can imitate Vivian's choice of footwear tomorrow, I see that she is in fact even worse off than me, wearing a pair of Birkenstock Sandals, toes so cold they have turned white. Curious, I ask if she's not uncomfortable, why didn't she chose to go around the lawn so she could walk on the paved path instead? She looks at me with surprise, 'but there is no time!'

$$
\text { [...] }
$$

We climb the stairs to the fourth floor where the client's apartment is located. As we're nearing the top, Berit instructs me to not approach the client. She describes him as mentally unstable, clarifying that he can become violent at times, 'but this will only take a minute, two at the most'. As we reach the fourth floor, Berit greets the care recipient, hands him his medicine and we're off again, rushing down the stairs. Briefly stopping to take the LMP out of her pocket Berit logs the visit, she smiles at me 'nine minutes saved'. [...]

Slamming the car door shut, Nora quickly logs the visit and starts the car, ignoring her seatbelt while I'm still struggling with mine. We continue down the street, parking 
a few hundred meters down. Again, she locks the car before I've managed to close my door and I worry that I am slowing her down. She jogs towards the apartment building.

[...]

Siri moves to the door and removes her shoe-covers, 'Ok, so we'll see each other tomorrow!' 'Ok, see you tomorrow' the client answers. As we go into the stairwell, Siri picks up the LMP to log the visit and sighs heavily ' 40 minutes instead of 25, we're going to have to make up for this somehow'.

[...]

I'm leaning over Anette's shoulder, using my mobile phone to videotape how she's operating the LMP to adjust the measurement of time when she logs the visit we just finished, she smiles into the camera 'We were able to make it in just 39 minutes [instead of 45]'

All visits to care recipients ended in a similar way. The homecare workers would activate the LMP, turn off the stopwatch, and log the proceedings. Invariably, all homecare workers uttered evaluative comments in reference to how much time they had spent with the care recipient as soon as they had activated the screen and gained access to the countdown. Most of the time, these comments were cheerful exclamations that they had been able to 'save time', but sometimes they would comment about having to compensate for the time that they 'lost'. Meanwhile, I was also making my own embodied experiences of time. However fast I moved and however well prepared I was, I always hurried to keep up and whatever I did I was never able to be quite as fast as the homecare workers. Going over my fieldnotes and reading through the transcripts, the homecare workers ways of talking about time and dealing with time by using the LMP, is everywhere.

\section{Talking about time}

All homecare workers describe how their workday is characterized by a lack of time, and that their ability to perform their work hinges on their capacity to make time. While varied in terms of personal style, there is a patterned consistency as all methods to make time serve to cut visits to homecare recipients shorter than they are supposed to be. Drawing on practice theory (Reckwitz, 2002; Shove et al., 2009), the homecare workers' descriptions of how they make time may be thought of as methods through which home care service workers act to co-configure accomplishments of time and the homecare product that is delivered to homecare recipients when experiencing harriedness.

\section{Cutting visits as short as possible}

By cutting visits to homecare recipients shorter than they are supposed to be, the homecare workers are able to save time. After finishing a visit to a homecare recipient, Lotte showed me the screen of her device. The screen displayed both the time that the administrators had allocated to the visit when they made her schedule, which was 40 minutes, and the time she had actually spent as measured by the device, which was 30 minutes. Lotte explained:

Lotte: See here, there was 40 minutes, but I [only spent 30 minutes] so I saved some time here.

Jenny: What can that time be used for? 
Lotte: Well, other things usually happen during the day so maybe I have to spend a bit of extra time in some places and then I have some time to spare.

When talking about making time, the homecare workers would distinguish between acceptable and unacceptable means and measures of making such cuts. To the homecare workers, the understanding that they must make time does not entail an understanding that visits to homecare recipients can be cut short in any which way. To be proficient in the skill of making time includes knowing the difference between cutting a visit as short as possible, and cutting it impossibly short.

\section{Against the stopwatch}

Accounts that contrasted between cutting visits possibly and impossibly short often drew on the stopwatch as metaphor for the estimated timeslots contained in the device they carried with them. In these descriptions, homecare workers distinguished between acceptable and unacceptable methods of making time by drawing boundaries between their own methods for making time and 'stopwatch care'. For instance, Ingvild describes how making time can be understood as part of care when it is contrasted against stopwatch care.

Ingvild: We try to use as little time as possible [when we make visits]. We steal time from [the homecare recipients] all the time. But if something happens, then we have to stay [with the homecare recipient]. For example, if the estimate says 10 minutes, but we need 20 minutes to resolve the issue, ok, then we stay for 20 minutes, so, it's not 'stopwatch care'. We don't ignore their needs [and let the LMP govern when we leave], but if we can save some time we do. We have to; otherwise, we won't have enough time to visit all of the care recipients.

During visits to homecare recipients' homes, the device continuously displays a measurement of the time spent in the form of a running clock, starting from 00:00. When the running clock reaches the amount of time allocated to that particular visit by administrators, the device signals to the homecare worker by shifting the colour of the numbers from green to red. When the homecare workers describe that they are not performing stopwatch care, they are referring to their ability to ignore this signal as well as the standardized timeslots.

The standardized timeslots are perceived as a 'cynical' way of limiting time during visits because homecare recipients' needs may change rapidly, and in ways that require unforeseen expenditures of time. To the homecare workers, time labor constitutes a caring alternative to stopwatch care because they understand themselves as able to make time while also taking homecare recipients' situational needs into account. Sometimes, this means that they will spend more time than estimated by administrators, sometimes they will spend less.

\section{Stealing, not depriving}

As Ingvild's description also illustrates, homecare workers would sometimes explicitly refer to acts of cutting visits to homecare recipients short as 'stealing', even when 
describing their methods of making time as part of caring for homecare recipients. While 'care' and 'stealing' are seemingly contradictive concepts, the homecare workers drew on a particular understanding of 'stealing' to distinguish between making time and victimizing homecare recipients. For example, Ingvild contrasts 'stealing time' against allowing the stopwatch to govern the allocation of time, which she describes as 'cynical'. Similarly, while Hanna describes making time as 'stealing', she simultaneously emphasizes that the homecare recipients are never deprived of anything:

Hanna: We don't stand there and talk just because we're supposed to be there for 10 minutes, we don't have the time for that [...] if we're going to be able to visit all the care recipients on the schedule, then we have to steal time from them [the homecare recipients], otherwise we won't be able to make it.

Jenny: does that mean that you defer tasks?

Hanna: It's not like, if we steal time from a homecare recipient it's not that they don't get breakfast or something like that. They get everything they need.

Rather than constitute an acknowledgment that they are doing something wrong, the homecare workers use of the term 'stealing' suggests an understanding that there is a difference between their own activities of making time by cutting visits to homecare recipients short and depriving the homecare recipient of something. To deprive homecare recipients of services they need, would make him or her a victim of negligence, as opposed to someone who is being cared for.

\section{Wasting time}

In speaking of acceptable ways of making time, the homecare workers would also distinguish between wasteful and purposeful uses of time. These accounts draw on homecare recipients' character traits when describing methods for making time. Crucially, wasting time was not understood as doing less for the homecare recipient, but rather that a homecare recipient has proved impossible to persuade into accepting services. As Ane explained:

Ane: $\quad$ She doesn't eat anything. She weighs 38 kilos.

Jenny: oh, do you give her nutritional drinks then or what do you do [in such a situation]?

Ane: We talked about starting with those drinks. But if we can't get her to eat we'll probably not be able to get her to drink those either [...] I can't get anything done here. I try, but then I leave. There's no point. I can't waste time standing there, there's no point, it won't make any difference. She is very stubborn, a very stubborn lady.

Other cases involve assistance to dress, shower, and make the bed. This is not an understanding restricted to homecare recipients with full cognitive capacity. Sometimes, the lack of full cognitive capacity is described as the cause for why persuasion is impossible. Many homecare workers identified dementia as an obstacle to care. For instance, Marianne explains that dementia typically manifests as refusal to accept help from 
anyone else than a particular person, and therefore constitutes acceptable grounds for any other homecare worker to make time by leaving and deferring tasks.

Marianne: she has dementia. [...]I'm sure she hasn't showered since I showered her 14 days ago, when the [other homecare workers] try, she refuses, so they leave. They can't get her into the shower, but I can.

The understanding that some homecare recipients are impossible to persuade is also entangled with notions of acceptable and unacceptable methods of making unwilling homecare recipients accept help. Homecare workers understood themselves as prohibited by law to force someone to accept help, whether that person retains capacity to consent or not. While persuasion is understood as acceptable, it is also understood as a process that is often time consuming. In time and through their reoccurring interactions with homecare recipients, the homecare workers accumulate knowledge regarding whether or not it is possible to persuade a homecare recipient. The homecare workers describe such knowledge as important when making decisions of whether or not to engages in persuasion at all. As Vivian explained:

Vivian: We can't force [the homecare recipients], but we can try to persuade them. We try to persuade them and usually we succeed if we spend time on [persuading them]. In time you get to know [the homecare recipients] and you know if there's any point in even trying [to persuade them].

\section{Win-win situations}

In other cases, the homecare workers describe non-performance of tasks as beneficial to homecare recipients and an opportunity to save time without depriving the homecare recipient of anything he or she needs. Berits' explanation of why she chooses to not do the washing up illustrates this understanding:

Berit: The kitchen was tidy. If we are performing tasks like [doing the washing up] it costs money so I don't do it unless it's necessary. Then I'll rather clean it tomorrow, maybe it's messier then. I try to avoid accumulating costs for them unless it's necessary, and this way I save a bit of time too.

To not perform tasks was sometimes described as beneficial to the homecare recipients' quality of life. Agnes' explanation of her grounds for deciding to not do the washing up describes deferring tasks as part of caring for the homecare recipient's wellbeing.

Agnes: $\quad$ There. She'll do the washing up. She has to do something. So I'll tell her when I leave that 'now you have some cups that must be cleaned'. If they're left standing for several days and she doesn't clean them, then I do it. But she has to be allowed to do her own washing up, you can't deprive them of everything. 


\section{The LMP goes to work}

So far, the analysis has mostly been concerned with the human homecare workers; however, when the homecare workers go to work, the LMP goes to work too. An understanding of the role of the LMP in relation to Time labor requires an understanding of the pre-digital history of the relationship between time and work in homecare, as well as the situated meaning of time spent in visits to care recipients.

Whenever I accompanied a homecare worker to observe their work with the LMP, I could observe that even though they commonly altered the measurement of time at the end of the visit, they always took care to ensure that the clock was running even if they could have refrained from activating it and still registered any measurement of their choosing. This raised the question of what meanings they attached to the activation of the 'stopwatch'.

In talking about their reasons for activating the clock, all homecare workers described how their workday is characterized by a lack of time, and that their ability to perform their work hinges on their capacity to make time. In this context, the capacity for the clock to function as a stopwatch is understood as important because it allows for the possibility to keep track of how much time they have spent during each visit. This is described as important because it allows them to keep track of how time they have at their disposal if they encounter problems that require them to spend more time than the estimates allow for.

Before the introduction of the LMP and its predecessor the GMP, the homecare workers used pen and paper to make notes about the observations they made when visiting the care recipient. As previously described, the LMP/GMP offers the possibility to register such observations in a handheld unit. This is the feature that is marketed by the producer as the LMP/GMP's capacity to 'give more time to care recipients' (Tieto Norway, 2015b). However, before the implementation of the LMP/GMP, the documentation of the visit to care recipients did not include accounts of how much time the homecare worker had spent with the individual care recipient. At that point in time, the organizational documentation of time in relationship to work was limited to managers documentation of when workers had started and finished their working day. In terms of governance, the implementation of the LMP/GMP is constitutive of a change in how time and homecare work are related to one another in organizational documentation of that work. Whether or not the resulting information is used for governing purposes in practice, attention with regards to an organizational interest in has been shifted from documentation of when homecare workers start and end their working days, to how much time they allocate to the completion of individual tasks. In this context, the LMP is constitutive of two modes of mediated presentation of the care interaction, the written account of the observations that the homecare worker has made regarding the current state of health of the care recipient, and the quantitative account of how much time that the homecare worker has spent with the care recipient.

\section{Time as representation of proficiency and tool for self-representation}

Until now, the analysis has described how homecare workers cut visits to care recipients shorter to save time. In such cases, the homecare workers abstained from making any 
adjustments to the registration of time before saving the documentation of the visit. That is, the documentation of time was consistent with the time that the homecare worker used during the visits. However, there were also visits when the homecare workers used more time than they should. In such cases, they always adjusted the measurement of time before finishing the documentation so that the registered time was consistent with the time allotted to that visit on their schedules.

Whenever I observed this behavior, I asked if turning time back was a way to avoid critique for using too much time. However, all homecare workers consistently rejected this understanding of the situation. All homecare workers expressed that a warranted need for more time is unproblematic and expected by the administrators. In talking about warranted need for more time, the homecare workers would often refer to the mental or physical health of care recipients. For instance, increasing physical frailty was described as a warranted need for more time because the care recipient become more dependent on the homecare worker to help them in and out of the shower, or understand why they need to shower, with the result that the visit will always take more time, even if the task itself has not changed. Similarly, medical emergencies, staying with the care recipient until medical professional arrived, and cases of death were described as unproblematically warranted uses of extra time.

Conversely, using more time in the absence of such reasons was a conversation topic most homecare workers avoided, particularly in relation to themselves in the situation at hand where they had just spent more time with a care recipient and turned the clock back when documenting the visit. In the few cases when the homecare workers did not change the topic of conversation, they tended to talk about using more time in depreciative terms. For instance, Ingvild described staying with a care recipient for reasons unrelated to their health as 'unprofessional'. Similarly, Agnes referred to the same action as 'a sign that you don't know what you a doing' and Berit described it as 'something everybody does [but only] in the beginning'. These accounts suggest an understanding of the time spent in visits to care recipients, where finishing the visit on time, or even before the time is up is treated as a signifier of professional competence. In this context, the documentation of time is not just a representation of the visit, but also a mode of self-representation where the professional self becomes available for evaluation, not only by others, but also by themselves. When homecare workers downplay the amount of time they need to finish their tasks by manipulating the clock, they are not just trying to live up to the expectations of their formal superiors, they are also shaping digitized representations of their professional selves in a manner that aligns this representation with a professional identity that they view as desirable.

\section{Conclusion}

This article has shown how homecare workers who work with a 'time-saving' ICT in the form of an app and experience a lack of sufficient time to do their tasks work to save time. By exploring how the homecare workers make sense of their own timesaving practices, the first part of the analysis illustrates the homecare workers methods of saving time. The second part of the analysis explores how the homecare workers makes sense of the technology in the context of time-saving and describes the role of the technology in relation to time-saving. However, empirical reality is always a mess and 
while the analytical description of these two dimensions of time labor separates them for practical purposes described in the methods section of this article, this separation should not be understood as an attempt to separate the technology from time-saving on an ontological level. The time-saving methods described in this article through the homecare workers understandings of their actions is not just something that occasionally relates to materiality - it is inherently sociomaterial. For instance, this article shows how time-saving includes the production of a digitalized professional self when homecare workers experience that the ability of performing work in a short amount of time is a sign of professional competence.

To the homecare workers, time-saving is ultimately about enabling themselves to do their work, despite experiencing a lack of time to do. Describing attempts to save time during visits to homecare recipients has become part of how they describe being able to manage their workload, as well as part of how they describe performing care. In other words, time-saving has become part of labor.

Previous studies of care work have often dealt with the lack of time in work as a problem. Indeed, many of the studies doing so are described in the introduction to this article. However, these studies have dealt with the lack of time in terms of a purely social phenomena and described it a source for stress and emotional labor (see, e.g., Blomgren \& Sahlin, 2007; Henriksson \& Wrede, 2008; Ericson-Lidman et al., 2013; Næss, 2003). Thus, in the context of other studies of care work and lack of time, a study about methods of ordering time to enable oneself to do ones work, and methods of using technology to order time as a strategical means to produce one's professional identity does stand out. Most of these previous studies draw on the concept emotional labor (Hochschild, 1983). When Hochschild (1983) coined this term, she described how stewardesses use emotional labor as a means of enabling them to accomplish services through the aesthetical production of a professional identity. Since then, studies of homecare work have often described how homecare workers use emotional labor to deal with a lack of time as part of labor, specifically experiences of stress when lacking enough time. Thus, these studies support the conclusion that informal efforts of enabling oneself to do ones job, and producing a professional identity are part of doing labor.

In the introductory section of this article, I also pointed out that previous studies of similar technologies highlight the importance of not taking the time-saving role of the technology for granted. Building on this statement, it is relevant to also point out that political discourse on the implementation of the time-saving ICTs in homecare work frame them as neutral instruments, the implementation of which will result in a given result - an unproblematic increase in the efficiency and quality of homecare services (Ministry of Health and Care Service, 2012). However, as domestication studies have shown through empirical exploration for a variety of technologies, the role of technologies and their implication is never given beforehand but emerges as the technology becomes embedded into their social contexts through users sense-making and practices of use. Thus, implementation of technology and its implications are never linear or predictable but always involve 'a slight surprise of action' (Latour, 1999). In the context of the political narrative outlined above, this study as well as other studies of time-saving technologies in homecare that have shown how time-saving technologies in homecare reproduce, and sometimes intensify, rather than resolve the lack of time (Bergschöld, 2016; Brown \& Korczynski, 2010; Hjalmarsson, 2009; Vuokko, 2006), may be considered a case in point. 
In introducing the concept of time labor, I am building on these studies and arguing for the merits of taking a sociomaterial approach to the commonsensical notion that workers who lack time will act to somehow resolve their problem and that their ways of doing so involves actors that are nonhuman. Crucially, a turn to sociomateriality emphasizes that agency is extended to nonhuman elements, while still abstaining from a technologically determinist perspective on this agency (Jarzabkowski \& Pinch, 2013; Oudshoorn \& Pinch, 2003). In this article, I singled out the role of a technology, but other nonhuman actors could have been considered to. For instance, the bodies of homecare recipients that sometimes facilitate and sometimes hinder time-saving, the vehicles that the homecare workers use to transport themselves between homecare recipients homes or even the landscape they need to traverse. This study has described methods of ordering time to enable oneself to do ones work, and methods of using technology to order time as a strategical means to produce one's professional identity. I offer the term time-labor, defined as sociomaterial enactments of ordering temporality that are an intrinsic part of workers labor conditions as well as their enactment of their professional identities as competent care workers. This does not mean to imply that this article provides an exhaustive account of time labor. As Buch and Andersen (2015) point out, a turn to practice-based perspectives like the one used here, can in itself be understood as a statement that speaks to the understanding of any practice as situated and contextual. But nor do I mean to imply that methods akin to time labor have not existed before, nor that they do not exist outside of homecare work. On the contrary, I think that the term time-labor is needed precisely because it captures a theme that has so far been neglected.

Recently, a special issue in this journal (Buch et al., 2015) showed how practice theory and practice-based studies can contribute to working-life studies. In one of the articles, Gherardi (2015) argues that a turn to practice in work life studies deepens our understanding of work precisely because it carries the possibility to further our capacity to analyse how different elements and dimensions of work are reified and made meaningful. Gherardi (2015) shows how relations with materialities in work are not limited to material affordances and delimitations and users possibilities of exploring and using such possibilities/potentialities, but also of the practices in which materialities become embedded. This study supports these arguments, but also show how a domestication approach to the role of technology may add to the analytical toolbox by offering possibilities to explicitly deal with assumptions that technologies (and other materialities) are constitutive of rational and predictable 'effects'.

\section{Conflict of Interest}

The author reports no conflict of interests.

\section{References}

Allebeck, P., \& Mastekaasa, A. (2004). Risk Factors for Sick Leave - General Studies. Scandinavian Journal of Public Health, (32), 49-108. doi: http://doi.org/10.1080/14034950410021853.

Berg, M., \& Mol, A. (1998). Differences in Medicine: Unravelling Practices, Techniques and Bodies. Durham: Duke University Press. 
Bergschöld, J. M. (2016). Domesticating Homecare: Vehicle Route Problem Solver Displaced. Nordic Journal of Science and Technology Studies, 4(2), 41-53.

Blomgren, M., \& Sahlin, K. (2007). Quests for Transparency: Signs of a New Institutional Era in the Health Care Field. In T. Christensen \& P. Lægreid (Eds.), Transcending New Public Management; The Transformation of Public Sector Reforms (pp. 155-177). Aldershot: Ashgate.

Brown, K., \& Korczynski, M. (2010). When Caring and Surveillance Technology Meet: Organizational Commitment and Discretionary Effort in Home Care Work. Work and Occupations, 37(3), 404-432. doi: http://doi.org/10.1177/0730888410373875.

Bryant, A., \& Charmaz, K. (2010). The SAGE Handbook of Grounded Theory: Paperback Edition. London, Thousand Oaks / New Delhi: SAGE Publications.

Buch, A., \& Andersen, V. (2015). Team and project work in engineering practices. Nordic Journal of Working Life Studies, 5(3a)(27). doi: http://doi.org/10.19154/njwls.v5i3a.4832.

Buch, A., Andersen, V., \& Klemsdal, L. (2015). Turn to Practice Within Working Life Studies. Nordic Journal of Working Life Studies, 5(Special Issue 3a: Practice Based Approaches to Working Life Studies). doi: http://doi.org/10.19154/njwls.v5i3a.4830.

Charmaz, K. (2014). Constructing Grounded Theory (2nd ed.). Thousand Oaks: Sage Publications.

Clarke, A. (2005). Situational analysis: Grounded theory after the postmodern turn. Sage.

Dawson, P., \& Sykes, C. (2016). Organizational Change and Temporality: bending the arrow of time. (Kindle edi). New York: Routledge.

Ericson-Lidman, E., Norberg, A., Persson, B., \& Strandberg, G. (2013). Healthcare personnel's experiences of situations in municipal elderly care that generate troubled conscience. Scandinavian Journal of Caring Sciences, 27(2), 215-223. doi: http://doi.org/10.1111/ j.1471-6712.2012.01017.x.

Evjen, T. (2008). IT og Helse/PDA prosjektet i det Digitale Trøndelag. Retrieved May 24, 2017, from https://www.google.no/url? sa=t\& $\mathrm{rct}=j \& q=\&$ esrc=s\&source=web\&cd $=11 \& v e d=0$ ahUKEwj5s8uFkIjUAhXCjSwKHUHKBj84ChAWCDEwAA\&url=http $\% 3 \mathrm{~A} \% 2 \mathrm{~F} \% 2 \mathrm{~F}-$ www.nokios.no $\% 2 \mathrm{~F} 2008 \% 2 \mathrm{Fpresentasjoner} \% 2 \mathrm{Fs} 2$ b1 te evjen.pdf\&usg=AFQjCNGIX8PV0t9LSxQRTLrOpc Iwo6P Q\&sig2=JesgI3f9qrR4c2H3qcl6CA\&.

Flaherty, M. G. (2003). Time Work: Customizing Temporal Experience. Social Psychology Quarterly, 66(1), 17-33. doi: http://doi.org/10.2307/3090138.

Gherardi, S. (2015). How the Turn to Practice may contribute to Working Life Studies. Nordic Journal of Working Life Studies2, 27(5/3a). doi: http://doi.org/10.19154/njwls. v5i3a.4831.

Gherardi, S., \& Rodeschini, G. (2016). Caring as a collective knowledgeable doing: About concern and being concerned. Management Learning,. Management Learning, 47(3), 266-284. doi: https://doi.org/10.1177/1350507615610030.

Henriksson, L., \& Wrede, S. (2008). Care Work in a Context of a Transforming Welfare State. In L. Henriksson, H. Host, \& S. Wrede (Eds.), Care Work in Crisis; Reclaiming the Nordic Ethos of Care (pp. 131-152). Lund: Studentlitteratur.

Hirvonen, H., \& Husso, M. (2012). Living on a Knife's Edge; Temporal Conflicts in Welfare Service Work. Time and Society, 21(3), 351-370. doi: http://doi.org/ $10.1177 / 0961463 \times 12454382$.

Hjalmarsson, M. (2009). New Technology in Home Help Services - a Tool for Support of an Instrument of Subordination. Gender, Work and Organization, 16(3), 368-384. doi: http://doi.org/10.1111/j.1468-0432.2009.00449.x.

Hochschild, A. (1983). The managed heart. Berkeley: University of California Press.

Holstein, J. A., \& Gubrium, J. F. (1995). The Active Interview. In D. Silverman (Ed.), Qualitative research: theory, method and practice (2nd ed., pp. 140-161). London, Thousand Oaks / New Delhi: Sage. 
Hughes, T. P. (1987). The Evolution of Large Technological Systems. In W. E. Bijker, T. P. Hughes, \& T. Pinch (Eds.), The Social Construction of Technological Systems: New Directions in the Sociology and History of Technology (pp. 51-82). Cambridge: MIT press.

Jarzabkowski, P., \& Pinch, T. (2013). Sociomateriality is 'the New Black': accomplishing repurposing, reinscripting and repairing in context. M@n@gement, 16(5),579-592. doi: http://doi.org/10.3917/mana.165.0579.

Latour, B. (1999). Pandora's hope: essays on the reality of science studies. Cambridge/London: Harvard university press.

Lee-Treweek, G. (1997). Women, resistance and care: An ethnographic study of nursing auxiliary work. Work, Employment \& Society, 11(1), 47-63. doi: http://doi.org/ 10.1177/0950017097111003.

Lie, M., \& Sørensen, K. H. (Eds.). (1996). Making technology our own?: domesticating technology into everyday life. Oslo: Scandinavian University Press.

Ministry of Health and Care Service. (2012). Future Care (Morgondagens Omsorg) Meld ST 29 (2012-2013) Report to the Storting (white paper). Oslo.

Mol, A. (2002). The Body Multiple: Ontology in Medical Practice. London: Duke University Press.

Mol, A. (2008). The Logic of Care: Health and the Problem of Patient Choice. New York: Routledge.

Mol, A., Moser, I., \& Pols, J. (2010). Care in Practice: On Tinkering in Clinics, homes and farms. (A. Mol, I. Moser, \& J. Pols, Eds.). Bielefeld: Transcript.

Næss, S. (2003). I tøffeste laget? Dokumentasjonsrapport on arbeidssituasjonen til ansatte $i$ pleie of omsorgstienesten [Too tough? Report on care workers conditions of labour. Bergen/Rokkansenteret Rapport 9/2003.

Næss, S., \& Wærness, K. (1996). Bedre omsorg? Kommunal eldreom-sorg 1980-1995. Bergen/SEFOS.

Nicolini, D. (2009). Zooming in and out: Studying practices by switching theoretical lenses and trailing connections. Organization Studies, 30(12), 1391-1418. doi: http://doi.org/ $10.1177 / 0170840609349875$.

Oudshoorn, N., \& Pinch, T. (2003). Introduction: How users and non-users matter. In N. Oudshoorn \& T. Pinch (Eds.), How users matter: The co-construction of users and technology. Cambridge: MIT Press.

Prestegård, S. (2015). Står på sitt. Eldrebyråd Aud Kvalbein slår tilbake. Det SV viser frem er en telefon og ikke en stoppeklocke mener hun [Stands her ground - the elder council Aud Kvalbein strikes back. What SV are showing is a phone and not a stopwatch]. Dagsavisen. Retrieved from http://www.dagsavisen.no/oslo/star-pa-sitt-1.369902.

Reckwitz, A. (2002). Toward a Theory of Social Practices A Development in Culturalist Theorizing. European Journal of Social Theory, 5(2), 243-263. doi: http://doi. org/10.1177/13684310222225432.

Reichertz, J. (2007). Abduction. The Logic of Discovery of Grounded Theory. In A. Bryant \& K. Charmaz (Eds.), The Sage Handbook of Grounded Theory (pp. 214-228). Sage.

Sandberg, T., \& Prestegård, S. (2015, June 23). Look here Kvalbein. Dagsavisen. Retrieved from http://www.dagsavisen.no/oslo/se-her-kvalbein-1.368650.

Schatzki, T. (2001). Introduction practice theory. In T. Schatzki, K. Knorr Cetina, \& E. von Sevigny (Eds.), The Practice turn in contemporary theory. London New York: Routledge.

Schatzki, T. R. (1996). Social practices: A Wittgensteinian approach to human activity and the social. Cambridge: Cambridge University Press.

Schatzki, T. R. (2011). Where the Action Is (On Large Social Phenomena Such as Sociotechnical Regimes). Retrieved from https:/www.google.no/url?sa=t\&rct=j\&q=\&es-

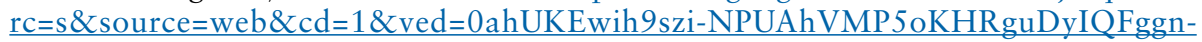


MAA\&url=http \%3A\%2F\%2Fwww.sprg.ac.uk\%2Fuploads\%2Fschatzki-wp1.pdf\&us$\mathrm{g}=\mathrm{AFQjCNEeE}$ wvJOD-6mmhjhPOdIDqV2GmZQ\&cad=rja.

Shove, E., Trentmann, F., \& Wilk, R. (2009). Time, consumption and everyday life: Practice, materiality and culture. New York: Berg.

Sørensen, K. (1996). Learning technology, constructing culture. Socio-technical change as social learning. (18/96).

Sørensen, K., Aune, M., \& Hatling, M. (2000). Against linearity - on the cultural appropriation of science and technology. In M. Teoksessa Dierkes \& C. Groete (Eds.), Between Understanding and Trust. The Public, Science and Technology. Amsterdam: Harwood.

Swidler, A. (1986). Culture in action: Symbols and strategies. American Sociological Review, 273-286.

Swidler, A. (2006). Talk of Love: Howculture matters. Chicago: University of Chicago Press.

Tieto Norway. (2015a). Lifecare Mobil Pleie. Retrieved October 7, 2015, from https://www. tieto.no/bransjer/helse-og-velferd/kommunal-helse-og-omsorg-tieto/lifecare-mobil-pleie.

Tieto Norway. (2015b). Tieto Lifecares mobile hjemmetjeneste gir mer tid til brukerne. Retrieved October 7, 2016, from https://www.tieto.no/nyheter/tieto-lifecares-mobile-hjemmetjeneste-gir-mer-tid-til-brukerne.

Tieto Velferd. (2016a). Lifecare Mobil Pleie. Retrieved May 23, 2017, from https://www. tieto.no/bransjer/helse-og-velferd/kommunal-helse-og-omsorg-tieto/lifecare-mobil-pleie.

Tieto Velferd. (2016b). Lifecare Mobil Pleie (brochure). Retrieved May 23, 2017, from https://www.tieto.no/sites/default/files/files/lifecare mobilpleie.pdf.

Vuokko, R. (2006). Work ethichs and effectiveness in home care: rationalization through technological innovation. In C. Zielinski, C. Duquenoy, \& K. Kimppa (Eds.), The Information Society: Emerging Landscapes (pp. 281-291). US: Springer.

Zerubavel, E. (1979). Patterns of time in hospital life. A sociological perspective. Chicago: University of Chicago Press.

Zerubavel, E. (1981). Hidden rythms Schedules and calendars in social life. Chicago: University of Chicago Press.

\section{End notes}

${ }^{1}$ A loose translation would be 'embarrassingly bad gadget'.

${ }^{2}$ This description is deliberately kept vague to ensure the anonymity of research participants.

${ }^{3}$ A videopresentation (in Norwegian) from 2009 of the functions in the GMP is available here. https://www.youtube.com/watch?v=VS9BBF8iqjA Scandinavian readers should be able to note the similarities between the LMP in the previously mentioned video and the older GMP presented here.

${ }^{4}$ Quotation marks in original. 